\title{
Front Matter: Volume 8924
}

, "Front Matter: Volume 8924," Proc. SPIE 8924, Fourth Asia Pacific Optical Sensors Conference, 892401 (15 October 2013); doi: 10.1117/12.2047039

SPIE. Event: Asia Pacific Optical Sensors Conference 2013, 2013, Wuhan, China 


\title{
Fourth Asia Pacific Optical Sensors Conference
}

\author{
Minghong Yang \\ Yunjiang Rao \\ Dongning Wang \\ Editors
}

15-18 October 2013

Wuhan, China

Organized by

Wuhan University of Technology (China)

University of Electronic Science and Technology of China (China)

The Hong Kong Polytechnic University (Hong Kong, China)

Harbin Engineering University (China)

Huazhong University of Science and Technology (China)

Sponsored by

NSFC-Natural Science Foundation of China

COS-Chinese Optics Society

Cooperating Organization and Publisher

SPIE 
The papers included in this volume were part of the technical conference cited on the cover and title page. Papers were selected and subject to review by the editors and conference program committee. Some conference presentations may not be available for publication. The papers published in these proceedings reflect the work and thoughts of the authors and are published herein as submitted. The publisher is not responsible for the validity of the information or for any outcomes resulting from reliance thereon.

Please use the following format to cite material from this book:

Author(s), "Title of Paper," in Fourth Asia Pacific Optical Sensors Conference, edited by Minghong Yang, Yunjiang Rao, Dongning Wang, Proceedings of SPIE Vol. 8924 (SPIE, Bellingham, WA, 2013) Article CID Number.

ISSN: 0277-786X

ISBN: 9780819498168

Published by

SPIE

P.O. Box 10, Bellingham, Washington 98227-0010 USA

Telephone +1 3606763290 (Pacific Time) · Fax +1 3606471445

SPIE.org

Copyright (C) 2013, Society of Photo-Optical Instrumentation Engineers.

Copying of material in this book for internal or personal use, or for the internal or personal use of specific clients, beyond the fair use provisions granted by the U.S. Copyright Law is authorized by SPIE subject to payment of copying fees. The Transactional Reporting Service base fee for this volume is $\$ 18.00$ per article (or portion thereof), which should be paid directly to the Copyright Clearance Center (CCC), 222 Rosewood Drive, Danvers, MA 01923. Payment may also be made electronically through CCC Online at copyright.com. Other copying for republication, resale, advertising or promotion, or any form of systematic or multiple reproduction of any material in this book is prohibited except with permission in writing from the publisher. The CCC fee code is 0277-786X/13/\$18.00.

Printed in the United States of America.

Publication of record for individual papers is online in the SPIE Digital Library.

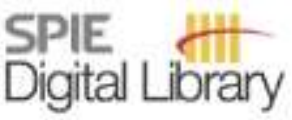

SPIEDigitalLibrary.org

Paper Numbering: Proceedings of SPIE follow an e-First publication model, with papers published first online and then in print and on CD-ROM. Papers are published as they are submitted and meet publication criteria. A unique, consistent, permanent citation identifier (CID) number is assigned to each article at the time of the first publication. Utilization of CIDs allows articles to be fully citable as soon as they are published online, and connects the same identifier to all online, print, and electronic versions of the publication. SPIE uses a six-digit CID article numbering system in which:

- The first four digits correspond to the SPIE volume number.

- The last two digits indicate publication order within the volume using a Base 36 numbering

system employing both numerals and letters. These two-number sets start with 00, 01, 02, 03, 04, $05,06,07,08,09,0 A, 0 B \ldots$. 0Z, followed by 10-1Z, 20-2Z, etc.

The CID Number appears on each page of the manuscript. The complete citation is used on the first page, and an abbreviated version on subsequent pages. Numbers in the index correspond to the last two digits of the six-digit CID Number. 


\title{
Contents
}

\author{
xv Conference Committee \\ xix Introduction
}

\section{SESSION 1 OPTICAL FIBERS FOR SENSING}

892402 Design and fabrication of a novel core-suspended optic fiber for distributed gas sensor [8924-5]

T. Zhang, L. J. Ma, H. B. Bai, C. G. Tong, Q. Dai, J. Yang, L. B. Yuan, Harbin Engineering Univ. (China)

892403 Optical fiber temperature sensor based on optical fiber delay [8924-40] N. Yang, Q. Qi, J. Su, Z.-Y. Wang, S.-J. Shi, Univ. of Electronic Science and Technology of China (China)

892404 Optically heated fiber Bragg grating in active fibers for low temperature sensing application 8924-43]

L. Qi, L. Jin, B.-O. Guan, Jinan Univ. (China)

892405 Enhancement of Brillovin scattering signal in pumped erbium-doped optical fiber [8924-50] M. Ding, N. Hayashi, Y. Mizuno, K. Nakamura, Tokyo Institute of Technology (Japan)

892406 Sensitivity improvement of UV FBG sensor by downsizing grating diameter [8924-81] I.-S. Song, C.-Y. Kim, H.-K. Kim, Chosun Univ. (Korea, Republic of); B.-H. Kim, Gwangju Institute of Science and Technology (Korea, Republic of); T.-J. Ahn, Chosun Univ. (Korea, Republic of)

892407 Producing regenerated gratings in hydrogen-loaded single mode fiber by heat treatment [8924-83]

H. YU, G. Li, X. Li, H. Guo, Wuhan Univ. of Technology (China)

892408 First-principles calculation of optical properties of germanium under pressure [8924-122] H. Chen, M. Li, Wuhan Univ. of Technology (China); N. B. Arsad, Univ. Kebangsaan Malaysia (Malaysia); S. Xie, Wuhan Univ. of Technology (China)

892409 Graded-index fiber tip optical tweezers [8924-137]

Y. Gong, A.-Y. Ye, Y. Wu, Y.-J. Rao, Y. Yao, S. Xiao, Univ. of Electronic Science and Technology of China (China)

8924 OA Refractive index insensitive temperature sensor based on coaxial waveguide fiber modal interferometer [8924-150]

A. Zhou, Q. XU, T. Zheng, J. Yang, Y. Yang, L. Yuan, Harbin Engineering Univ. (China)

8924 OC High-sensitivity temperature sensor based on highly-birefringent microfiber [8924-165] L.-P. Sun, J. Li, L. Jin, S. Gao, Z. Tian, Y. Ran, B.-O. Guan, Jinan Univ. (China)

8924 OD Dual optical tweezers integrated in a four-core fiber: design and simulation [8924-166] Y. Zhang, L. Yuan, Z. Liu, J. Yang, Harbin Engineering Univ. (China) 
8924 OE Developing new active optical fibres with broadband emissions (Invited Paper) [8924-210] G.-D. Peng, The Univ. of New South Wales (Australia); J. Zhang, Harbin Engineering Univ. (China); Y. Luo, Z. Sathi, A. Zareanborji, The Univ. of New South Wales (Australia);

J. Canning, The Univ. of New South Wales (Australia) and The Univ. of Sydney (Australia)

8924 OF All-fiber Bessel beam generator based on M-type optical fiber [8924-212]

H. Deng, L. Yuan, Harbin Engineering Univ. (China)

SESSION 2 COMPONENT TECHNOLOGIES FOR SENSING

8924 OG Fiber optic three-component seismometer [8924-2]

D. Jiang, W. Zhang, F. Li, Institute of Semiconductors (China)

$8924 \mathrm{OH} \quad$ Side-core holey fiber based plasmonic sensor [8924-14]

Y. Han, L. Xia, D. Liu, Huazhong Univ. of Science and Technology (China)

$8924 \mathrm{Ol}$ Optical fiber relative-humidity sensor using Fabry-Perot cavity formed by e-beam evaporated dielectric films [8924-19]

D. Lee, W. Xie, M. Yang, Wuhan Univ. of Technology (China); Y. Zhang, Z. Zhuang, Institute of Structural Mechanics (China)

8924 0J High precision optical fiber Fabry-Perot sensor for gas pressure detection [8924-22] Y. Mao, Wuhan Univ. of Technology (China) and Air Force Early Warning Academy (China); X. Tong, Wuhan Univ. of Technology (China)

8924 OK Pulse selection technique in fiber sensing [8924-41]

L. Zhang, P. LU, D. Liu, Huazhong Univ. of Science and Technology (China)

$8924 \mathrm{OL} \quad$ High-resolution fiber carbon monoxide sensing system and its data processing [8924-58] T. Zhang, Y. Wei, Y. Li, Y. Zhao, T. Liu, C. Wang, Shandong Key Lab. of Optical Fiber Sensors (China) and Shandong Academy of Sciences (China)

8924 OM High-speed frequency swept light source used for grating demodulator [8924-59] P. Han, Wuhan Univ. of Technology (China)

8924 ON A novel miniature fiber optic magnetic field sensor based on Ampere force and dualpolarization fiber laser [8924-79]

Z. Guo, L. Cheng, J. Han, B.-O. Guan, L. Jin, Jinan Univ. (China); B. Chen, X.-H. Lin, Shenzhen Univ. (China)

892400 Fiber Mach-Zehnder interferometer based on multi-mode fiber and up-taper for curvature sensing applications [8924-85]

L. Mao, P. Lu, Z. Lao, D. Liu, Huazhong Univ. of Science and Technology (China)

8924 OP Reduction of the effect of the overflow reset in resonant frequency servo loop for resonator fiber optic gyro [8924-88]

X. Lu, X. YU, H. Ma, Z. Jin, Zhejiang Univ. (China) 
$89240 Q \quad$ Fiber in-line Michelson Interferometer for refractive index sensing [8924-105]

C. R. Liao, The Hong Kong Polytechnic Univ. (Hong Kong, China) and Shenzhen Univ. (China); D. N. Wang, The Hong Kong Polytechnic Univ. (Hong Kong, China); M. Wang,

M. Yang, Wuhan Univ. of Technology (China); Y. Wang, Shenzhen Univ. (China)

8924 OR Efficiency improvement of an optical fiber fluorescent temperature sensor using a spherical fiber probe design [8924-121]

Y.-S. XU, M. Li, Wuhan Univ. of Technology (China)

8924 OS Study on side-polished plastic optical fiber used as line source [8924-159]

X. Yu, W. He, C. Zhang, C. Wang, M. Yang, Wuhan Univ. of Technology (China)

8924 OT Side-polished fiber sensing for determination of azimuthal orientation of nematic liquid crystal [8924-160]

Y. Han, Z. Chen, J. Yu, H. Li, X. He, Jinan Univ. (China)

8924 OU Blade tip timing vibration monitoring method based on fiber Bragg [8924-179]

F. WU, L. Liang, J. Xing, L. Wang, L. Jia, Wuhan Univ. of Technology (China)

8924 OV Highly sensitive current sensor utilizing CrNi-wire supported microfiber coils [8924-182]

X. Xie, J. Li, L.-P. Sun, L. Jin, B. Guan, Jinan Univ. (China)

8924 OW Active radiation hardening technology for fiber-optic source [8924-185]

Y. Yang, X. Suo, M. Yang, BeiHang Univ. (China)

8924 0X Intensity-modulated strain sensor based on fiber Mach-Zehnder interferometer employing core-offset [8924-189]

J. Zhou, C. Liao, Y. Wang, K. Yang, X. Zhong, Z. Li, Y. Liu, G. Wang, Shenzhen Univ. (China)

8924 OY Characteristics research of self-amplified distributed feedback fiber laser [8924-205]

Z. Song, H. Qi, J. Guo, C. Wang, Key Lab. of Optical Fiber Sensoring Technology of

Shandong Province (China); G. Peng, The Univ. of New South Wales (Australia)

$89240 Z$ Femtosecond laser inscription and micromachining in novel flexible glass flat-fibre chips [8924-206]

K. Kalli, Cyprus Univ. of Technology (Cyprus); C. Markos, Hellenic Research Foundation

(Greece); A. Posporis, C. Koutsides, Cyprus Univ. of Technology (Cyprus);

C. Riziotis, National Hellenic Research Foundation (Greece); A. S. Webb, J. K. Sahu,

C. Holmes, J. C. Gates, P. G. R. Smith, Univ. of Southampton (United Kingdom)

892410 Experimental validation of applied strain sensors: importance, methods and still unsolved challenges (Invited Paper) [8924-211]

W. R. Habel, V. G. Schukar, F. Mewis, H. Kohlhoff, Bundesanstalt für Materialforschung und prüfung (Germany)

892411 Analysis of highly birefringent microfibers devices with FV-FDBPM [8924-209]

H.-F. Xuan, W. Jin, J. Ma, W. Jin, The Hong Kong Polytechnic Univ. (Hong Kong, China) 
892412 Distributed dynamic strain measurement using long-gauge FBG and DTR 3 interrogator based on delayed transmission/reflection ratiometric reflectometry [8924-11] M. Nishiyama, H. Igawa, T. Kasai, Japan Aerospace Exploration Agency (Japan); N. Watanabe, Tokyo Metropolitan Univ. (Japan)

892413 Novel demodulation method for eliminating Rayleigh scattering in Raman distributed temperature sensors using anti-Stokes light only [8924-56]

Z. L. Wang, J. Chang, S. S. Zhang, G. P. Lv, B. N. Sun, S. Jiang, S. Luo, X. H. Liu, Y. N. Liu, W. J. Wang, Z. Liu, Shandong Univ. (China); X. Z. Liu, Shandong Academy of Sciences (China)

892414 Experimental characterization of Brillouin scattering in an all-solid photonic bandgap fiber for sensing application [8924-71]

B. Han, H. Liang, J. Li, L. Cheng, B. Guan, Jinan Univ. (China)

892415 High-spatial-resolution fast Brillouin optical fiber sensor for distributed dynamic measurement based on differential double-pulse [8924-74]

Y. Dong, T. Jiang, D. Zhou, D. Ba, Harbin Institute of Technology (China); H. Zhang, Harbin Univ. of Science and Technology (China); Z. Lu, Harbin Institute of Technology (China);

L. Chen, X. Bao, Univ. of Ottawa (Canada)

892416 A signal processing system of fiber Bragg grating sensor based on code division multiplexing access [8924-80]

W. Li, Wuhan Univ. of Technology (China)

892417 Multi-point location algorithm for distributed optical fiber disturbances detection system [8924-82]

H. Wang, Q. Sun, X. Li, J. Wo, D. Liu, Huazhong Univ. of Science and Technology (China)

892418 Proposal and simulation of differential double-pulse pair Brillovin optical time-domain analysis [8924-161]

J. Tang, Wuhan Univ. of Technology (China); W. Lu, B. Chen, Changjiang River Scientific Research Institute (China); H. Guo, C. Zhang, Wuhan Univ. of Technology (China)

892419 Development of a distributed fiber sensor for simultaneous strain and vibration measurement [8924-198]

F. Wang, X. Zhang, X. Wang, Nanjing Univ. (China)

8924 1 A 142.2km BOTDA based on ultra-long fiber laser with a ring cavity [8924-204]

X.-H. Jia, Univ. Of Electronic Science and Technology of China (China) and Sichuan Normal Univ. (China); Y.-J. Rao, Z.-N. Wang, W.-L. Zhang, C.-X. Yuan, X.-D. Yan, J. Li, H. Wu,

Y.-Y. Zhu, F. Peng, Univ. of Electronic Science and Technology of China (China)

\section{SESSION 4 INTEGRATED TECHNOLOGIES FOR SENSING}

8924 1B Diaphragm-based fiber optic Fabry-Perot hydrophone with hydrostatic pressure compensation [8924-3]

Z. Wang, W. Zhang, F. Li, Institute of Semiconductors (China) 
8924 1C Hydraulic decoking on-line monitoring system based on the optical fiber sensing technology [8924-25]

D. Zhong, Wuhan Univ. of Technology (China) and Hubei Univ. of Science and Technology (China); X. Tong, T. Ji, Wuhan Univ. of Technology (China)

8924 ID Application of optical fiber sensing technology in the hydraulic decoking monitoring system [8924-31]

Y. Fan, X. Tong, T. Ji, X. Gao, D. Zhong, Wuhan Univ. of Technology (China)

8924 IE Applications of asymmetric distributed-feedback fiber laser in sensor array system [8924-48]

P. P. Wang, J. Chang, C. G. Zhu, G. P. Lv, Shandong Univ. (China); Y. J. Zhao, Shandong Univ. (China) and Shandong Academy of Sciences (China); X. L. Zhang, Z. H. Sun, G. D. Peng, Shandong Academy of Sciences (China) and The Univ. of New South Wales (Australia); S. S. Zhang, Z. Liu, Shandong Univ. (China)

8924 IF Acoustic emission source linear localization based on an ultra-short FBGs sensing system [8924-129]

Z. Jin, M. Jiang, Q. Sui, F. Zhang, L. Jia, Shandong Univ. (China)

$89241 G$ Dual-wavelength distributed feedback fiber laser with dual symmetrical m phase shifts [8924-133]

H. Qi, Z. Song, J. Guo, J. Chang, C. Wang, Shandong Academy of Sciences (China);

G.-D. Peng, Shandong Academy of Sciences (China) and The Univ. of New South Wales (Australia)

$89241 \mathrm{H} \quad$ Research on microseismic energy calculation and duration automatically picking [8924-146]

G. Song, B. Hu, J. Wang, J. Guo, T. Liu, Key Lab. of Optical Fiber Sensoring Technology of Shandong Province (China) and Shandong Academy of Sciences (China)

$892411 \quad H o i s t$ fault diagnosis system based on optical fiber vibration sensor [8924-149]

L. Zhao, J. Wang, Shandong Academy of Sciences (China); K. Liu, L. Yang, Yanzhou Mining Group (China)

$89241 \mathrm{~J}$ A cross-correlation based fiber optic white-light interferometry with wavelet transform denoising [8924-151]

Z. Wang, Y. Jiang, W. Ding, R. Gao, Beijing Institute of Technology (China)

8924 1K Characterization of fiber optic Cerenkov radiation sensor for detecting neutrons [8924-152]

K. W. Jang, Konkuk Univ. (Korea, Republic of); T. Yagi, C. H. Pyeon, Kyoto Univ. (Japan);

S. H. Shin, W. J. Yoo, Konkuk Univ. (Korea, Republic of); T. Misawa, Kyoto Univ. (Japan);

B. Lee, Konkuk Univ. (Korea, Republic of)

$89241 \mathrm{~L}$ Demonstration of low pulse repetition frequency erbium-doped fiber lasers [8924-169]

Y. Ran, Y. Luo, L. Xia, C. Yang, D. Liu, Huazhong Univ. of Science and Technology (China)

8924 IM Distributed vibration sensing based on time-difference pulses [8924-171]

Q. He, T. Zhu, X. Xiao, Chongqing Univ. (China); X. Bao, Univ. of Ottawa (Canada) 
8924 IN Fiber optic Cerenkov radiation sensor system to estimate burn-up of spent fuel: characteristic evaluation of the system using Co-60 source [8924-175]

S. H. Shin, K. W. Jang, D. Jeon, S. Hong, S. G. Kim, H. I. Sim, W. J. Yoo, Konkuk Univ. (Korea, Republic of); B. G. Park, Soonchunhyang Univ. (Korea, Republic of); B. Lee, Konkuk Univ. (Korea, Republic of)

892410 Low coherence tandem interferometry for the measurement of differential length sensing at two widely separated locations [8924-195]

M. D. Smith, W. N. MacPherson, R. R. J. Maier, Heriot-Watt Univ. (United Kingdom)

8924 IP A novel fiber optical vibration defending system with on-line intelligent identification function [8924-196]

H. Wu, X. Xie, H. Li, X. Li, Y. Wu, Y. Gong, Y. Rao, Univ. of Electronic Science and Technology

of China (China)

8924 IQ The nanostructure of silica microfibers fabricated by microfluidic self-assembly [8924-124] J. Canning, M. Ma, The Univ. of Sydney (Australia); B. Gibson, The Univ. of Melbourne (Australia); G. Huyang, The Univ. of Sydney (Australia); A. Beavis, D. Bishop, Univ. of Technology, Sydney (Australia); K. Cook, The Univ. of Sydney (Australia); A. McDonagh, Univ. of Technology, Sydney (Australia); J. Shi, The Univ. of Sydney (Australia); D. Shi, G.-D. Peng, The Univ. of New South Wales (Australia); M. Crossley, The Univ. Of Sydney (Australia)

8924 IR The viscous properties of silica in the 1000-1200 C window of extreme fibre sensing (Invited Paper) [8924-143]

J. Canning, The Univ. of Sydney (Australia); L.-Y. Shao, The Univ. of Sydney (Australia) and The Hong Kong Polytechnic Univ. (Hong Kong, China)

8924 is Development of fiber optic radiation sensor for gamma-ray spectroscopy: comparative study on efficiency of LYSO:Ce, YSO:Ce, and BGO scintillation crystals [8924-177] D. Jeon, W. J. Yoo, S. H. Shin, S. Hong, S. G. Kim, H. I. Sim, K. W. Jang, Konkuk Univ. (Korea, Republic of); S. Cho, Soongsil Univ. (Korea, Republic of); B. Lee, Konkuk Univ. (Korea, Republic of)

8924 IT Nonlinear optical transmission of lead phthalocyanines in polymeric matrix [8924-178] C.-X. Sheng, R. Z. Wang, H. Li, Q. Chen, Nanjing Univ. of Science and Technology (China); R. A. Norwood, College of Optical Sciences, The Univ. of Arizona (United States)

$89241 \mathrm{U}$ Determination of complex refractive index of graphene waveguide by microfiber knot sensor [8924-183]

B. Yao, Y. Wu, Y. Cheng, Y. Rao, Y. Gong, Z. Wang, Y. Chen, Univ. of Electronic Science and Technology of China (China)

8924 IV A fluorescence study of self-assembled silica layers on D-shaped optical fibre [8924-187] L. Moura, J. Canning, L. Lindoy, K. Cook, M. Crossley, The Univ. of Sydney (Australia); Y. Luo, G.-D. Peng, The Univ. of New South Wales (Australia); L. Glavind, M. Kristensen, Aarhus Univ. (Denmark) 
8924 IW Micromolded U-shaped PDMS optical waveguide for biosensing applications [8924-64] N. Punjabi, A. Khatri, S. Mukherji, Indian Institute of Technology Bombay (India)

8924 1X Optic fiber pulse-diagnosis sensor of traditional Chinese medicine [8924-72] J. S. Ni, Shandong Academy of Sciences (China); W. Jin, B. N. Zhao, X. L. Zhang, Shandong Univ. (China); C. Wang, S. J. Li, F. X. Zhang, Shandong Academy of Sciences (China); G. D. Peng, The Univ. of New South Wales (Australia)

$89241 Y$ Spectral absorption gas sensor based on anti-resonant reflecting optical waveguide [8924-84]

H. Yu, Y. Zheng, H. Guo, B. Cao, Wuhan Univ. of Technology (China); H. Wei, Yangtze Optical Fibre and Cable Co., Ltd. (China)

$89241 Z$ Optical fiber oxygen sensor based on DFB laser absorption spectroscopy [8924-93] Y. Zhao, Y. Wei, T. Zhang, Y. Li, W. Zhao, L. LV, T. Liu, C. Wang, Shandong Academy of Sciences (China)

892420 A novel bio-detecting chip based on the opened fiber surface plasmon enhancement mechanism [8924-102]

G. Wang, Shenzhen Univ. (China) and North Univ. of China (China); Y. Wang, C. Liao, J. Zhou, Shenzhen Univ. (China)

892421 Measurement methods in trace water vapor concentration detection system based on direct absorption spectroscopy [8924-112]

G. P. LV, J. Chang, S. S. Zhang, Q. P. Wang, Y. N. Liu, Shandong Univ. (China); X. Z. Liu, Shandong Academy of Sciences (China); Z. Liu, Q. Wang, W. J. Wang, Z. L. Wang, S. Jiang, C. G. Zhu, W. Wei, Shandong Univ. (China)

892422 Research progress of photonic crystal fibers for gas sensing [8924-156]

L. LV, Y. Wei, T. Liu, Shandong Academy of Sciences (China)

892423 Effect of light source on Kretschmann surface plasmon resonance sensor [8924-162] C. Gong, H. Gao, L. Hua, M. Li, Wuhan Univ. of Technology (China)

892424 S-shaped SU-8 optical waveguide immobilized with gold nanoparticles for trace detection of explosives [8924-176]

R. Bharadwaj, R. Tripathi, A. Prabhakar, S. Mukherji, Indian Institute of Technology Bombay (India)

892425 Gas sensor based on hollow-core photonic crystal fibers with high relative sensitivity [8924-188]

L. Duan, Y. Lu, C. Hao, B. Wu, J. Yao, Tianjin Univ. (China)

892426 Surface plasmon resonance refractive index sensor based on polymer photonic crystal fibers with nano-composite materials [8924-194]

C. Hao, Y. Lu, B. Wu, L. Duan, M. Mayilamu, J. Yao, Tianjin Univ. (China) 
892427 Photonic microcells for novel devices and sensor applications (Invited Paper) [8924-207] C. Wang, W. Jin, Shenzhen Research Institute (China) and The Hong Kong Polytechnic Univ. (Hong Kong, China); J. Ma, The Hong Kong Polytechnic Univ. (Hong Kong, China); W. Jin, The Hong Kong Polytechnic Univ. (Hong Kong, China); H. L. Ho, Shenzhen Research Institute (China)

\section{SESSION $7 \quad$ INDUSTRIAL APPLICATIONS AND FIELD TESTS}

892428 Cable tunnel fire experiment study based on linear optical fiber fire detectors [8924-12] D. Fan, H. Ding, Wuhan Univ. of Technology (China)

892429 On-line power transformer partial discharge monitoring based on the optical fiber sensing technology [8924-28]

K. Wang, X. Tong, Wuhan Univ. of Technology (China); J. Hu, X. Zhu, Wuhan Univ. (China)

8924 2A Fiber optic displacement sensor used in railway turnout contact monitoring system [8924-46]

H. XU, Institute of Semiconductors (China) and Shijiazhuang Tiedao Univ. (China); W. Zhang, Institute of Semiconductors (China); Y. Du, Shijiazhuang Tiedao Univ. (China); F. Li, Institute of Semiconductors (China) and Shijiazhuang Tiedao Univ. (China); F. Li, Institute of Semiconductors (China)

$89242 B \quad$ The application of fiber grating sensing technology in the safety monitoring of railway's protective net in slopes [8924-70]

L. Li, D. Zhang, Y. Guo, Wuhan Univ. of Technology (China)

8924 2C The monitoring system of the pipeline safety of the coal mine gas drainage based on the optic fiber sensing technology [8924-86]

Y. Li, Y. Wei, T. Zhang, Y. Zhao, L. LV, T. Liu, Shandong Key Lab. of Optical Fiber Sensors (China) and Shandong Academy of Sciences (China)

8924 2D Train overload and unbalanced load detection based on FBG gauge [8924-87] J. Pan, W. Li, X. Dai, Wuhan Univ. of Technology (China)

$89242 \mathrm{E}$ Research and application of optical fiber sensing technology in wireless temperature monitoring of switchgear [8924-100]

W. Gan, C. Zhang, Wuhan Univ. of Technology (China)

8924 2F Distributed fiber optic microseismic monitoring system for coal mines [8924-138]

B. Hu, T. Liu, J. Wang, G. Song, Shandong Academy of Sciences (China)

$89242 \mathrm{G}$ Optical fiber sensors to improve the safety of nuclear power plants [8924-144]

P. Ferdinand, S. Magne, G. Laffont, Lab. de Mesures Optiques, CEA (France)

$89242 \mathrm{H} \quad$ Spectroscopic analysis on scintillating and Cerenkov lights generated in dual-mode fiber optic dosimeter [8924-167]

W. J. Yoo, S. H. Shin, D. Jeon, S. Hong, S. G. Kim, H. I. Sim, K. W. Jang, Konkuk Univ. (Korea, Republic of); S. Cho, Soongsil Univ. (Korea, Republic of); B. Lee, Konkuk Univ. (Korea, Republic of) 
$892421 \quad$ Study of coal mine belt conveyor state on-line monitoring system based on DTS [8924-197]

Y. Wei, Shandong Academy of Sciences (China); W. Wu, Yanzhou Coal Mining Co.

(China); T. Liu, Shandong Academy of Sciences (China); Y. Sun, Yanzhou Coal Mining Co. (China)

8924 2J Research on optical fiber flow test method with non-intrusive [8924-202]

Y. Shang, X. Liu, C. Wang, W. Zhao, Shandong Academy of Sciences (China) and Key Lab. of Optical Fiber Sensoring Technology of Shandong Province (China)

$89242 \mathrm{~L}$ Thermal-optical properties of microbubbles for sensing applications [8924-52]

Y. Yang, OIST Graduate Univ. (Japan) and National Engineering Lab. for Fiber Optics Sensing Technology (China); J. Ward, S. Nic Chormaic, OIST Graduate Univ. (Japan)

$89242 \mathrm{~N}$ Investigation of tilted long period fiber gratings in fiber tapers [8924-65]

Y. Li, X. Zhang, F. GU, F. Pang, Y. Liu, T. Wang, Shanghai Univ. (China)

892420 Highly sensitive hydrostatic pressure sensor based on a selectively filled photonic crystal fiber [8924-76]

M. Lin, L. Jin, Jinan Univ. (China); Y. Wang, Wuhan Institute of Technology (China);

B.-O. Guan, Jinan Univ. (China)

$89242 \mathrm{P}$ Sensitivity enhanced magnetic field sensor based on Farady effect and dual-polarization fiber grating laser [8924-78]

J. Han, L. Cheng, Z. Guo, B.-O. Guan, L. Jin, Jinan Univ. (China); B. Chen, X.-H. Lin, Shenzhen Univ. (China)

$89242 R \quad$ Monitoring intracranial pressure based on F-P [8924-95]

T. Cai, X. Tong, Wuhan Univ. of Technology (China); G. Chen, Wuhan Univ. (China)

892425 Wide absorption spectrum measuring methods by DFB-LDs in water vapor detection system [8924-97]

Y. N. Liu, J. Chang, J. Lian, Q. Wang, G. P. Lv, W. J. Wang, Z. Liu, Shandong Univ. (China);

X. Z. Liu, Shandong Academy of Sciences (China); S. S. Zhang, Z. L. Wang, S. Jiang,

C. G. Zhu, W. Wei, B. N. Sun, Shandong Univ. (China)

$89242 \mathrm{~T}$ Chemical etching process for PANDA polarization-maintaining fiber in HiBi fiber loop mirror [8924-98]

J. Wang, C. Zhou, A. Zheng, Wuhan Univ. of Technology (China)

$89242 \mathrm{U} \quad$ Micro-fiber inclinometer based on deformation of FBG [8924-172]

Q. Zhang, T. Zhu, Chongqing Univ. (China); K. S. Chiang, City Univ. of Hong Kong (Hong Kong, China)

$89242 \mathrm{~V}$ Temperature-independent displacement sensor based on the chirped grating in a microfiber taper [8924-173]

X. Shen, J. Li, L.-P. Sun, Y. Ran, L. Jin, B. Guan, Jinan Univ. (China) 
8924 2W Microfiber Fabry-Perot filter consisting of two cascaded Sagnac reflectors for multiwavelength fiber laser [8924-192]

W. Jia, Q. Sun, X. Sun, J. Wo, D. Liu, Huazhong Univ. of Science and Technology (China)

8924 2X Inner air-cavity based fiber in-line Mach -Zehnder interferometer fabricated by femtosecond laser and fusion splicing [8924-193]

T. Y. Hu, The Hong Kong Polytechnic Univ. (Hong Kong, China); Y. Wang, The Hong Kong Polytechnic Univ. (Hong Kong, China) and Wuhan Institute of Technology (China);

C. R. Liao, D. N. Wang, The Hong Kong Polytechnic Univ. (Hong Kong, China)

$89242 Y \quad$ Optimization of plasmonic sensors in visible and infrared regime (Invited Paper) [8924-201] B. Lee, T. Chung, K. Lee, Y. Lee, J. Cho, Seoul National Univ. (Korea, Republic of)

$89242 Z$ High sensitivity pressure sensor based on a birefringent microfiber loop mirror [8924-208] W. Jin, H. Xuan, C. Wang, W. Jin, The Hong Kong Polytechnic Univ. (Hong Kong, China)

$892430 \quad$ Pressure sensing with optical fiber-tip air bubbles [8924-240]

W. Yu, C. Fu, Wuhan Institute of Technology (China); D. N. Wang, The Hong Kong Polytechnic Univ. (Hong Kong, China); Y. Wang, Wuhan Institute of Technology (China) and The Hong Kong Polytechnic Univ. (Hong Kong, China)

\section{SESSION 9 GRATING-BASED SENSING}

$892431 \quad$ Feasibility of multi-parameter measurement for FBG perimeter security sensor [8924-10] C. Zhang, L. Wang, Wuhan Univ. of Technology (China)

892432 Fabrication and characterization of a polymer micro-fiber Bragg grating [8924-18] G. Rajan, G.-D. Peng, The Univ. of New South Wales (Australia)

892433 Hydrogen performance of fiber Bragg grating hydrogen sensors using Pt-loaded $\mathrm{WO}_{3}$ coating as sensing materials [8924-20]

J. Dai, M. Yang, Z. Yang, Z. Li, Y. Wang, Wuhan Univ. of Technology (China); Y. Zhang, Z. Zhuang, Institute of Structural Mechanics (China)

892434 An interrogation system based on two semiconductor optical amplifiers for weak fiber Bragg gratings [8924-30]

Z. Luo, Wuhan Univ. of Technology (China) and China Three Gorges Univ. (China); H. Wen, H. Guo, Wuhan Univ. of Technology (China)

892435 Long period grating-based microfiber Mach-Zehnder interferometer for sensing applications [8924-42]

Y. Tan, L.-P. Sun, L. Jin, J. Li, B.-O. Guan, Jinan Univ. (China)

892436 Stabilizing the beat signal of the polarimetric heterodyning fiber grating laser sensor [8924-54]

Y. Liang, Q. Yuan, L. Jin, L. Cheng, B.-O. Guan, Jinan Univ. (China) 
892437 Enhanced resolution of long-period grating bend sensor [8924-55]

L. Glavind, Vestas Wind Systems A/S (Denmark) and Aarhus Univ. (Denmark); S. Gao, The Univ. of Sydney (Australia) and Zhejiang Univ. (China); K. Cook, J. Canning, The Univ. of Sydney (Australia); B. F. Skipper, Aarhus Univ. (Denmark); Y. Luo, G. Peng, The Univ. of New South Wales (Australia); M. Kristensen, Aarhus Univ. (Denmark)

892438 FBG laser sensing with polarization scrambling [8924-77]

H. Kim, D. Kim, M. Song, Chonbuk National Univ. (Korea, Republic of)

892439 FBG monitoring on a viaduct of urban railway [8924-89]

W. Li, J. Pang, X. Lu, J. Liu, C. Zhou, Wuhan Univ. of Technology (China)

8924 3A Plasma post-processing of diamond-like carbon nano-coated long-period gratings [8924-103]

M. Śmietana, A. Krysiński, Warsaw Univ. of Technology (Poland); W. J. Bock, P. Mikulic, Univ. du Québec en Outaouais (Canada)

8924 3B All-fiber time-delay spectrometer based on an array of fiber Bragg gratings [8924-114] T. Tiess, M. Rothhardt, M. Jäger, Institut für Photonische Technologien e.V. (Germany); H. Bartelt, Institut für Photonische Technologien e.V. (Germany) and Friedrich Schiller Univ. Jena (Germany)

$89243 \mathrm{C} \quad$ Long period fiber gratings written in photonic crystal fibers by $\mathrm{CO}_{2}$ laser [8924-126] Y. Wang, Shenzhen Univ. (China); W. Jin, D. Wang, The Hong Kong Polytechnic Univ. (Hong Kong, China); C. Liao, X. Zhong, Z. Li, J. Zhou, Y. Liu, Shenzhen Univ. (China)

8924 3D Application of the fiber Bragg grating (FBG) sensors in coal mines [8924-141] J.-Y. Wang, G.-D. Song, B. Hu, Shandong Academy of Sciences (China); L. Li, Shandong Micro-Sensor Photonics, Ltd. (China); T. Liu, Shandong Academy of Sciences (China) and Shandong Micro-Sensor Photonics, Ltd. (China)

$89243 \mathrm{E} \quad$ Long term stability of spectral measurement systems for fiber Bragg grating sensors [8924-145]

N. Roussel, P. Ferdinand, L. Maurin, Lab. de Mesures Optiques, CEA (France)

8924 3F FBG strain sensibilized monitor on railway switch pole [8924-163]

W. Li, J. Liu, J. Pan, J. Pang, X. Lu, C. Zhou, Wuhan Univ. of Technology (China)

$89243 G \quad$ Spectral characteristics of long-period chiral fiber gratings fabricated by stepping system [8924-180]

Y. Zhang, H. XU, L. Yang, Univ. of Science and Technology of China (China)

$89243 \mathrm{H}$ Differential FBG sensor for temperature-independent refractive index measurement [8924-190]

S. Gao, L. Jin, L.-P. Sun, J. Li, B.-O. Guan, Jinan Univ. (China)

Author Index 
Proc. of SPIE Vol. $8924892401-14$

Downloaded From: https://www.spiedigitallibrary.org/conference-proceedings-of-spie on 26 Apr 2023 Terms of Use: https://www.spiedigitallibrary.org/terms-of-use 


\title{
Conference Committees
}

\author{
Conference Chairs
}

Minghong Yang, Wuhan University of Technology (China)

Yunjiang Rao, University of Electronic Science and Technology of China (China)

Dongning Wang, The Hong Kong Polytechnic University (Hong Kong, China)

International Steering Committee

Ralph P. Tatam, Cranfield University (United Kingdom)

Xiaoyi Bao, University of Ottawa (Canada)

Hartmut Bartelt, Institute of Photonics (Germany)

Arthur Braga, Pontificia Universidade Católica do Rio de Janeiro (Brazil)

John Canning, The University of Sydney (Australia)

Andrea Cusano, Universitá degli Studi del Sannio (Italy)

Bai-Ou Guan, Jinan University (China)

Banshi D. Gupta, Indian Institute of Technology, Delhi (India)

Kazuo Hotate, University of Tokyo (Japan)

Desheng Jiang, Wuhan University of Technology (China)

Wei Jin, The Hong Kong Polytechnic University (Hong Kong, China)

Hypolito Kalinowski, Universidade Tecnológica Federal do Paraná (Brazil)

Martin Kristensen, Arhus Universitet (Denmark)

Byoungho Lee, Seoul National University (Korea, Republic of)

Yanbiao Liao, Tsinghua University (China)

Tongyu Liu, Shandong Academy of Sciences (China)

Yu-Lung Lo, National Cheng Kung University (Taiwan, China)

Alexis Mendez, MCH Engineering (United States)

Kyunghwan Oh, Yonsei University (Korea)

Bertrand Poumellec, Université Paris-Sud (France)

Yunjiang Rao, University of Electronic Science and Technology of

China (China)

David Sampson, University of Western Australia (Australia)

José Luís Santos, Universidade do Porto (Portugal)

Perry Shum, Nanyang Technological University (Singapore)

Hwayaw Tam, The Hong Kong Polytechnic University

(Hong Kong, China)

Frederique Vanholsbeeck, University of Auckland (New Zealand)

Anbo Wang, Virginia Polytechnic Institute and State University (United States)

Reinhardt Willsch, Institute of Photonics (Germany) 
Technical Program Committee Chairs

Minghong Yang, Wuhan University of Technology (China)

Perry Shum, Nanyang Technological University (Singapore)

Yunjiang Rao, University of Electronic Science and Technology of China (China)

Technical Program Committee

Athikom Roeksabutr, Mahanakorn University of Technology (Thailand)

Dongning Wang, The Hong Kong Polytechnic University (Hong Kong, China)

Scott Wade, Swinburne University (Australia)

Wei Jin, The Hong Kong Polytechnic University (Hong Kong, China)

Brant Gibson, University of Melbourne (Australia)

Tiegen Liu, Tianjin University (China)

Anna Mignani, Instituto di Fisica Applicata "Nello Carrara," Consiglio Nazionale delle Ricerche (Italy)

Arnan Mitchell, RMIT University (Australia)

Chang Wang, Shandong Academy of Sciences (China)

Halina Rubinsztein-Dunlop, University of Queensland (Australia)

John Arkwright, Commonwealth Scientific and Industrial Research

Organisation (Australia)

John Canning, The University of Sydney (Australia)

Min Gu, Swinburne University of Technology (Australia)

Kyriacos Kalli, Cyprus University of Technology (Cyprus)

Mark Prescott, Monash University (Australia)

David Webb, Aston University (United Kingdom)

Xiaoyi Bao, University of Ottawa (Canada)

Jayantha Epaarachchi, University of Southern Queensland (Australia)

Simon Fleming, The University of Sydney (Australia)

N. Granpayeh, Khaje Nasir Toosi University of Technology

(Iran, Islamic Republic of)

Zuyuan He, Shanghai Jiaotong University (China)

Gang-Ding Peng, The University of New South Wales (Australia)

Xuping Zhang, Nanjing University (China)

Wende Zhong, Nanyang Technological University (Singapore)

David Moss, The University of Sydney (Australia)

Kevin Chen, Pittsburgh University (United States)

Muhammad Khawar Islam, University of Engineering and Technology Taxila (Pakistan)

Martin Kristensen, Aarhus Universitet (Denmark)

Sarun Sumriddetchkajorn, National Electronics and Computer Technology Center (Thailand)

Graham Town, Macquarie University (Australia) 
John Ballato, The Center for Optical Materials Science and Engineering Technologies (COMSET), Clemson University (United States)

Somnath Bandyopadhyay, Central Glass and Ceramic Research Instiute (CGCRI) (India)

Adrian Carter, Nufern (United States)

Zhe Chen, Jinan University (China)

Kin Seng Chiang, City University of Hong Kong (Hong Kong, China)

Yasufumi Enami, Hiroshima University (Japan)

Sheng-Lung Huang, National Taiwan University (Taiwan, China)

Shibin Jiang, Advalue Company (United States)

Ming-jun Li, Corning Inc. (United States)

Cicero Martelli, Universidade Tecnológica Federal do Paraná (Brazil)

Tanya Monro, University of Adelaide (Australia)

Libo Yuan, Harbin Engineering University (China)

Wolfgang Ecke, Institute of Photonics (Germany)

Jacques Albert, Carleton University (Canada)

Kevin Cook, The University of Sydney (Australia)

Xingyong Dong, China Jiliang University (China)

Bai-Ou Guan, Jinan University (China)

Morten Ibsen, Optoelectronics Research Centre (ORC), Southampton University (United Kingdom)

Matthieu Lancry, Université Paris-Sud (France)

Byoungho Lee, Seoul National University (Korea, Republic of)

De-Yuan Shen, Fudan University (China)

Lei Xu, Fudan University (China)

Jim Katsifolis, Future Fibre Technologies (Australia)

Yong Huang, Comcore (China)

Hypolito Kalinowski, Universidade Tecnológica Federal do Paraná (Brazil)

Tongyu Liu, Shandong Academy of Sciences (China)

Alexis Mendez, MCH Engineering (United States)

Hwayaw Tam, The Hong Kong Polytechnic University (Hong Kong, China)

Shuqiang Zhang, Yangtze Optical Fibre and Cable Company Ltd. (China)

Bertrand Poumellec, Université Paris-Sud (France)

John Ballato, Clemson University (United States)

Minghong Yang, Wuhan University of Technology (China)

Martin Kristensen, Aarhus Universitet (Denmark)

Arnan Mitchell, RMIT University (Australia)

Ciming Zhou, Wuhan University of Technology (China)

Local Organising Committee

Dian Fan, Wuhan University of Technology (China)

Xiaoyan Wen, Wuhan University of Technology (China) 
Donglai Guo, Wuhan University of Technology (China)

Cheng Cheng, Wuhan University of Technology (China)

Jianguan Tang, Wuhan University of Technology (China)

Ciming Zhou, Wuhan University of Technology (China)

Xinyan Bai, Wuhan University of Technology (China)

Jiaguo Xiong, Wuhan University of Technology (China)

Session Chairs

Plenary Session

Wei Jin, The Hong Kong Polytechnic University (Hong Kong, China)

Yunjiang Rao, University of Electronic Science and Technology of China (China)

Gilberto Brambilla, The University of Southampton (United Kingdom)

Optical Fibers for Sensing

John Canning, The University of Sydney (Australia)

Component Technologies for Sensing

Qian Li, University of Toronto (Canada)

Distributed and Networked Sensing

Zuyuan He, Shanghai Jiaotong University (China)

Integrated Technologies for Sensing

Libo Yuan, Harbin Engineering University (China)

Novel Materials for Sensing

Byoungho Lee, Seoul National University (Korea, Republic of)

Chemical and Biological Sensing

Perry Shum, Nanyang Technological University (Singapore)

Industrical Applications and Field Tests

Wolfgang Habel, Federal Institute for Materials Research and Testing (Germany)

Physical Sensing

Dongning Wang, The Hong Kong Polytechnic University (Hong Kong, China)

Grating-based Sensing

Gang-Ding Peng, The University of New South Wales (Australia) 
SPIE Student Award Session Chairs

Desheng Jiang, Wuhan University of Technology (China)

Brian Culshaw, University of Strathclyde (United Kingdom)

Proc. of SPIE Vol. $8924892401-19$

Downloaded From: https://www.spiedigitallibrary.org/conference-proceedings-of-spie on 26 Apr 2023 Terms of Use: https://www.spiedigitallibrary.org/terms-of-use 
Proc. of SPIE Vol. 8924 892401-20

Downloaded From: https://www.spiedigitallibrary.org/conference-proceedings-of-spie on 26 Apr 2023 Terms of Use: https://www.spiedigitallibrary.org/terms-of-use 


\section{Introduction}

The Asia Pacific Optical Sensors (APOS) Conference series was launched in 2008, in Chengdu China, and alternates approximately every 18 months with major global sensing conferences such as International Conference on Optical Fiber Sensors. With the success of the second event in 2010 in Guangzhou, China, the APOS was well-recognized in the specific region. In 2012 the third series was held outside of China for the first time, reflecting the broader growth of optical sensing research and development within the Asia Pacific region, bringing APOS to international maturity as the region's premier optical sensing conference. The third APOS conference was held in Sydney, a great success was clear with many participants not only in the Asia-Pacific region, but also from America and Europe.

Once again the APOS conference moved back to China, where research and development in optics sensing technologies was among the hottest topics. The fourth AsiaPacific Optical Sensors Conference 2013 (APOS 2013) held in Wuhan, Hubei, China 15 to 18 October 2013. The Conference was organized by Wuhan University of Technology, and co-organized by University of Electronic Science and Technology of China, the Hong Kong Polytechnic University, Harbin Engineering University, Huazhong University of Science and Technology. As chairs we appreciate all the efforts contributed to the successful organization of this conference. Especially, we want to express our gratitude to the local organizing committee; without your great support, a successful event would not be possible.

The conference has clearly built up its reputation as the region's essential forum for reporting and exchanging the latest progress in optical and photonic sensing technologies. It has become the regions première meeting point for academic researchers, technical and business professionals, and end user industries to share and exchange their ideas and R\&D experiences. Similar to Optical Sensors (OSA topical meeting) in America, and European Workshop on OFS in Europe, the APOS will be the perfect platform for people in optics sensing community in the Asia-Pacific region.

Wuhan is the capital of Hubei Province, and is the most populous city in central People's Republic of China. It lies at the intersection of the middle reaches of the Yangtze and Han River; Now, Wuhan is recognized as the political, economic, financial, cultural, educational and transportation center of central China. Particularly Wuhan is the home of so-called Optics Valley of China (OVC) with hundreds of institutions and companies engaging in optics-related technologies, including optical fibers, optical cables, optically active and passive devices, and optical communication systems.

Welcome to the fourth APOS, welcome to Wuhan. 
Proc. of SPIE Vol. 8924 892401-22

Downloaded From: https://www.spiedigitallibrary.org/conference-proceedings-of-spie on 26 Apr 2023 Terms of Use: https://www.spiedigitallibrary.org/terms-of-use 